\title{
Comerciar con Occidente. Las placas de marfil y hueso de la caja de madera de la estancia 100 de Casas del Turuñuelo (Guareña, Badajoz, España): contexto arqueológico e iconográfico, análisis y restauración
}

Trade with the West: the ivory and bone plaques of the wooden box of the Room 100 of Casas del Turuñuelo (Guareña, Badajoz, Spain): archaeological and iconographic context, analysis and restoration

ESTHER RodRíGUEZ GONZÁLEZ

Instituto de Arqueología (CSIC - Junta de Extremadura)

Plaza de España, 15, E-06800 Mérida

esther.rodriguez@iam.csic.es

\section{Sebastián Celestino Pérez}

Instituto de Arqueología (CSIC - Junta de Extremadura) Plaza de España, 15, E-06800 Mérida scelestino@iam.csic.es

\section{Ana M. Herranz Redondo}

Instituto de Arqueología (CSIC - Junta de Extremadura) Plaza de España, 15, E-06800 Mérida

anam.herranz@hotmail.com

José Miguel Morillo León

Universidad de Gotemburgo. Departamento de Estudios Históricos Lundgrensgatan 5, 41256 Göteborg (Suecia)

jmiguelmorillo@gmail.com 
Durante la primera campaña de excavaciones realizada en el año 2015 en el yacimiento tartésico de Casas del Turuñuelo (Guareña, Badajoz) se procedió a excavar la denominada estancia 100. Entre los materiales arqueológicos documentados sobre el pavimento de la habitación se recuperaron cuatro placas que por la posición que presentaban decoraban las cuatro caras de una caja de madera perdida por el incendio que puso fin a la vida del edificio. Este trabajo reúne la información referente a su hallazgo y contexto arqueológico, el estudio de las piezas y su iconografía, los resultados de los análisis realizados tanto de las placas como de los clavos conservados, así como el proceso de restauración y conservación al que las piezas han sido sometidas. Su estudio nos ha permitido abrir nuevas líneas de investigación en torno al comercio fenicio con Occidente y la existencia de un artesanado especializado en el trabajo del hueso y el marfil en los enclaves peninsulares.

\section{PALABRAS CLAVE}

TARTESO, VALLE MEDIO DEL GUADIANA, COMERCIO MEDITERRÁNEO, MARFIL, HIPOPÓTAMO, HUESO

During excavations at the Tartessic site of Casas del Turuñuelo (Guareña, Badajoz) in 2015, the so-called room 100 was excavated. Among the archaeological materials documented on the floor of the room, four plates were recovered in primary position and seems to point that they decorated the four faces of a wooden box lost by the fire that put an end to the life of the building. This work gathers the information referring to its find and archaeological context. This also applies the study of the objects and their iconography, the results of the analyzes carried out both on the plates and the preserved nails, as well as the restoration and conservation process to which the pieces objects have been submitted. This study has allowed us to launch new research lines around Phoenician trade with the West and the existence of a craftsman specialized in the work of bone and ivory, in peninsular enclaves.

\section{KEYWORDS}

TARTESSUS, CENTRAL GUADIANA VALLEY, MEDITERRANEAN TRADE, IVORY, HIPPOPOTAMUS, BONE

\section{Introducción}

En el año 2014 comenzaron los trabajos arqueológicos en el yacimiento tartésico de Casas del Turuñuelo (Guareña, Badajoz). Dicho enclave se localiza en la comarca natural de las Vegas Altas dentro del cauce medio del río Guadiana (fig. la). Pertenece a la categoría de asentamientos denominada "edificios tartésicos ocultos bajo túmulo» (Rodríguez González, 2018); una categoría exclusiva de este territorio que tiene su auge entre finales del siglo vi e inicios del siglo IV aC. La denominación que reciben estos yacimientos deriva del modelo de amortización al que fueron sometidos estos grandes edificios. Así, tras su clausura e incendio, las construcciones se colmatan con adobes, arcillas y arenas hasta rellenar por completo todas las estancias en las que previamente se han dispuesto los objetos arqueológicos también amortizados. El resultado es la generación de unos túmulos artificiales 

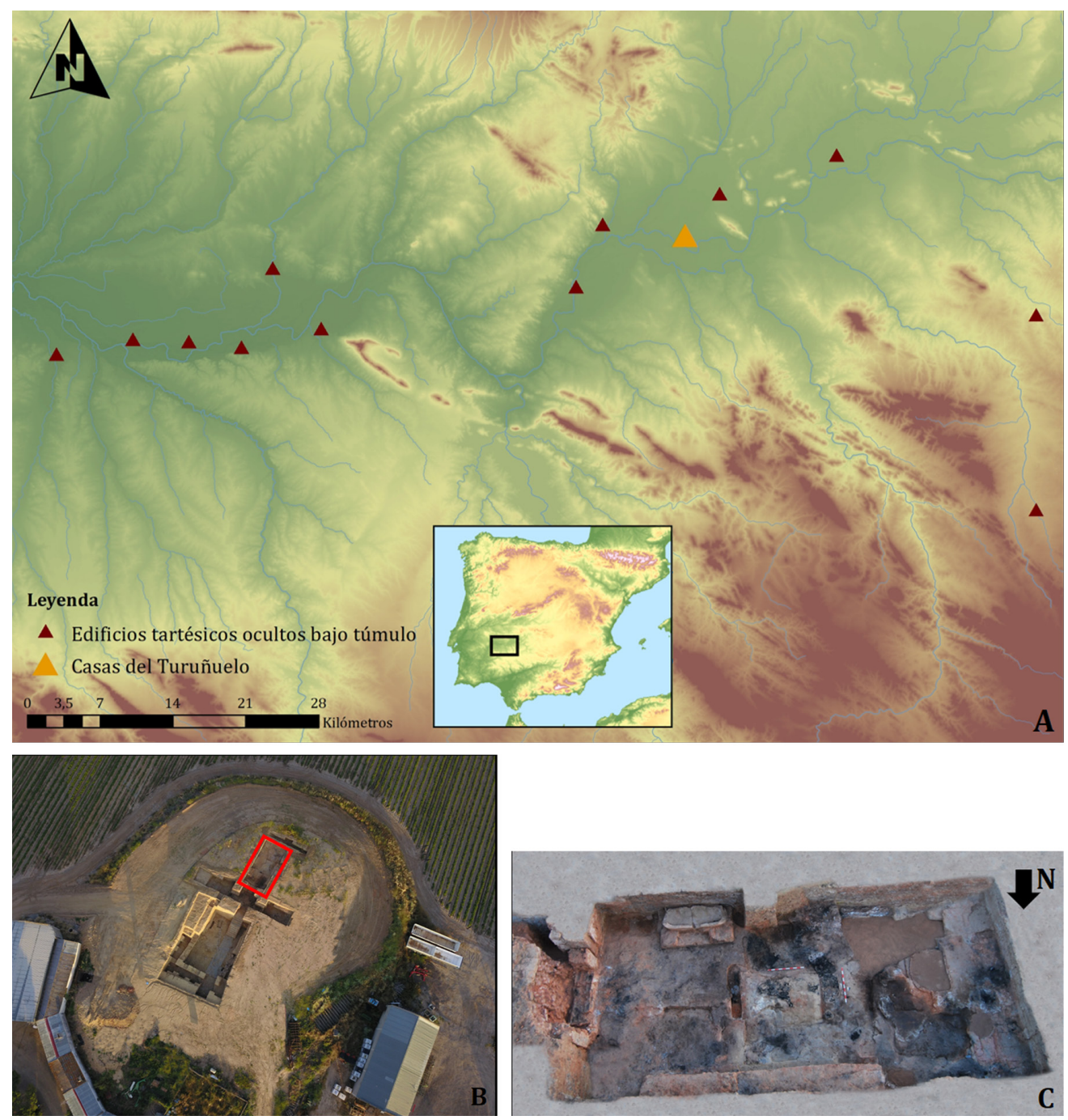

Figura 1. Localización del yacimiento de Casas del Turuñuelo. A) Mapa de localización del enclave dentro del valle medio del Guadiana. B) Fotografía aérea del túmulo. El recuadro rojo marca la locación de la estancia 100 dentro del área excavada. C) Vista aérea de la estancia 100 del Turuñuelo (diseño: Esther Rodríguez González, @Construyendo Tarteso).

que han pasado desapercibidos en el paisaje hasta nuestros días gracias, en buena medida, al sellado final mediante una gruesa capa arcilla que ha impedido que los materiales se esparzan por el exterior (fig. lb).

La ejecución de un primer sondeo estratigráfico, cuyo objetivo era la realización de una columna polínica (Celestino y Rodríguez González, 2017: 44) permitió localizar la 
que hasta la fecha es la estancia de mayores dimensiones de las excavadas en el yacimiento. La estancia principal o $\mathrm{H}-100$ tiene $70 \mathrm{~m}^{2}$ de extensión, una planta rectangular y un único acceso ubicado al este, en eje con la escalera monumental que preside el patio y que da acceso al piso superior, donde se localiza esta habitación (Rodríguez González y Celestino, 2017). La presencia de numerosos detalles arquitectónicos, caso de los bancos corridos, del altar en forma de piel de toro en el centro de la estancia o la "bañera» ubicada sobre un pedestal de adobe adosado al muro sur, nos ha llevado a plantear un uso cultual para este espacio (Rodríguez González y Celestino, 2017: 191) (fig. 1c).

Entre los materiales arqueológicos recuperados sobre el pavimento de la estancia cabe señalar el destacado conjunto de platos y cuencos, a partir de los cuales ha podido diseñarse una tipología para las producciones documentadas en el yacimiento (Rodríguez González y Celestino, 2017: 189, fig. 9). Estas piezas han sido puestas en relación con la existencia de un gran banquete ritual al final de la vida del edificio, relacionado a su vez con la hecatombe de animales recientemente documentada en su patio y actualmente en estudio (Celestino y Rodríguez González, 2019; Rodríguez González y Celestino, 2019). Junto al conjunto de platos pudo recuperarse otro tipo de materiales, caso de las esteras de esparto que cubrían parte del pavimento de la estancia (Marín Aguilera et al., 2019), de varias piezas de marfil y hueso entre las que se localiza un fragmento que todavía conserva la lámina de oro que decora su filo (Rodríguez González y Celestino, 2017: 190, fig. 10b) o las cuatro placas objeto de estudio en este trabajo.

A la espera de los resultados derivados del estudio geomagnético que se está llevando a cabo a partir del análisis de los ladrillos y los niveles de uso del yacimiento, claramente afectados por el incendio que puso fin a la vida del edificio, y que nos permitirá tener una fecha muy aproximada al momento final del enclave, la cronología del yacimiento, fechado en el siglo v aC, procede de la alta presencia de cerámicas áticas localizadas (Celestino et al., 2017), así como de otras piezas que se están moviendo por el Mediterráneo en esas cronologías, caso de la escultura de mármol o el conjunto de vidrios documentado en el patio. No obstante, en el yacimiento se atesoran piezas de cronología más antigua, a modo de reliquias, siguiendo el mismo patrón que el documentado en Cancho Roano (Zalamea de la Serena, Badajoz). Es dentro de este contexto donde se inserta la pieza que analizaremos a continuación, cuya cronología puede equiparase a las producciones eborarias documentadas en el Bajo Guadalquivir en yacimientos como el Bencarrón (Alcalá de Guadaira, Sevilla) y la Cruz del Negro (Carmona, Sevilla).

Aunque dos de las placas ya han sido analizadas desde el punto de vista iconográfico en sendos trabajos, actualmente en proceso de publicación, donde se abordan cuestiones muy concretas como el análisis tipológico de las embarcaciones de la placa norte o el estudio de la escena presente en la placa oeste donde el león se asocia con la representación de una embarcación, este trabajo tiene como objetivo completar esa información presentando una serie de datos inéditos entre los que se encuentra el contexto arqueológico donde fueron halladas las placas, su descripción iconográfica, los resultados de los análisis macroscópicos y de espectrometría de infrarrojos por transformada de Fourier (FTIR) realizados y gracias a los 
cuales hemos podido conocer las materias primas con las que fueron fabricadas, así como una breve reseña de su proceso de restauración y de aquellos aspectos que sobre la producción de las placas hemos conocido gracias a la realización de estos trabajos.

La combinación de todos estos datos permite sacar algunas conclusiones en torno a la posible procedencia de este tipo de piezas de clara raíz oriental y, por lo tanto, de la existencia de un nutrido comercio mediterráneo entre los siglos IX y VI aC, así como de los mecanismos de llegada de algunos de estos materiales a la península ibérica, no solo a los enclaves fenicios de la costa, sino hasta las tierras del interior. Así mismo, la originalidad técnica de buena parte de los marfiles peninsulares nos permite plantear la existencia de talleres occidentales en los que, sin embargo, predomina una iconografía de estilo orientalizante.

\section{Contexto arqueológico del hallazgo}

Las placas se documentaron sobre el pavimento de la estancia 100 en su sector oeste (fig. 2a). Por la disposición que presentaban (fig. 2b), formando un rectángulo perfecto, así como por la conservación de dos de sus clavos, es evidente que se trata de placas que decoraban una caja de madera o estuche de forma ligeramente trapezoidal, hoy perdida por el incendio que sufrió el edificio, incendio que afectó también el estado de conservación de las piezas, como valoraremos más adelante, que pudieron recuperarse casi íntegramente, pero muy fragmentadas, razón por la cual el proceso de restauración ha resultado fundamental para su estudio detallado.

Del cribado de la tierra localizada en el interior de las placas se recuperó un conjunto de 56 cuentas de pasta vítrea de color verdoso y de diferente diámetro que podrían haber formado parte de un objeto de adorno personal, tal vez una pulsera o un collar (fig. 3). El estado de conservación de las cuentas es bastante deficiente como consecuencia de las altas temperaturas alcanzadas por el incendio que provocó que muchas de ellas se fundieran hasta fusionarse y conformar un conglomerado de pasta vítrea completamente informe que complica su análisis y estudio.

\section{Descripción de las placas y análisis iconográfico}

Las cuatro placas fueron identificadas y clasificadas en función de la orientación que tenían en el lugar de su aparición. Las dos placas mayores corresponden a las caras norte y sur de la caja, mientras que las menores se localizan en sus extremos este y oeste. ${ }^{1}$ Cada una de

1. Para facilitar la comprensión en la descripción iconográfica de las placas y de las relaciones que establecemos entre ellas, hemos numerado las piezas del 1 al 4: sur (1), oeste (2), norte (3) y este (4). 


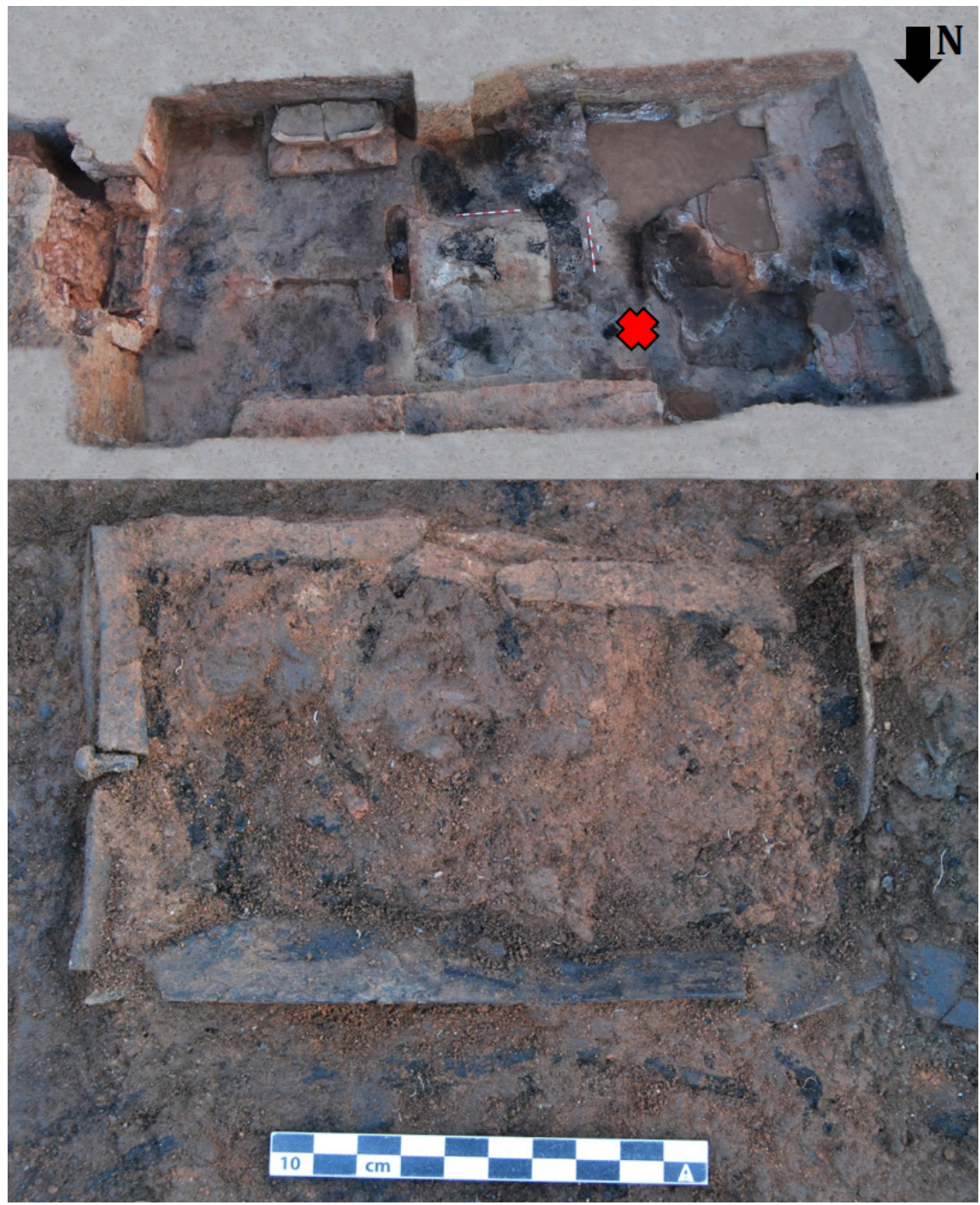

Figura 2. Localización de las placas sobre el pavimento de la estancia 100 y fotografía en la que se aprecia su disposición (montaje: Esther Rodríguez González, (C) Construyendo Tarteso).

ellas presenta un motivo iconográfico diferente, aunque todas comparten un mismo proceso de fabricación. Todas han sido realizadas siguiendo la técnica de la incisión, un sistema característico de los marfiles de producción tartésica que los diferencia claramente de las producciones llegadas de Oriente, donde predominan técnicas como el bajorrelieve, la incrustación, el calado o el bulto redondo (fig. 4). 


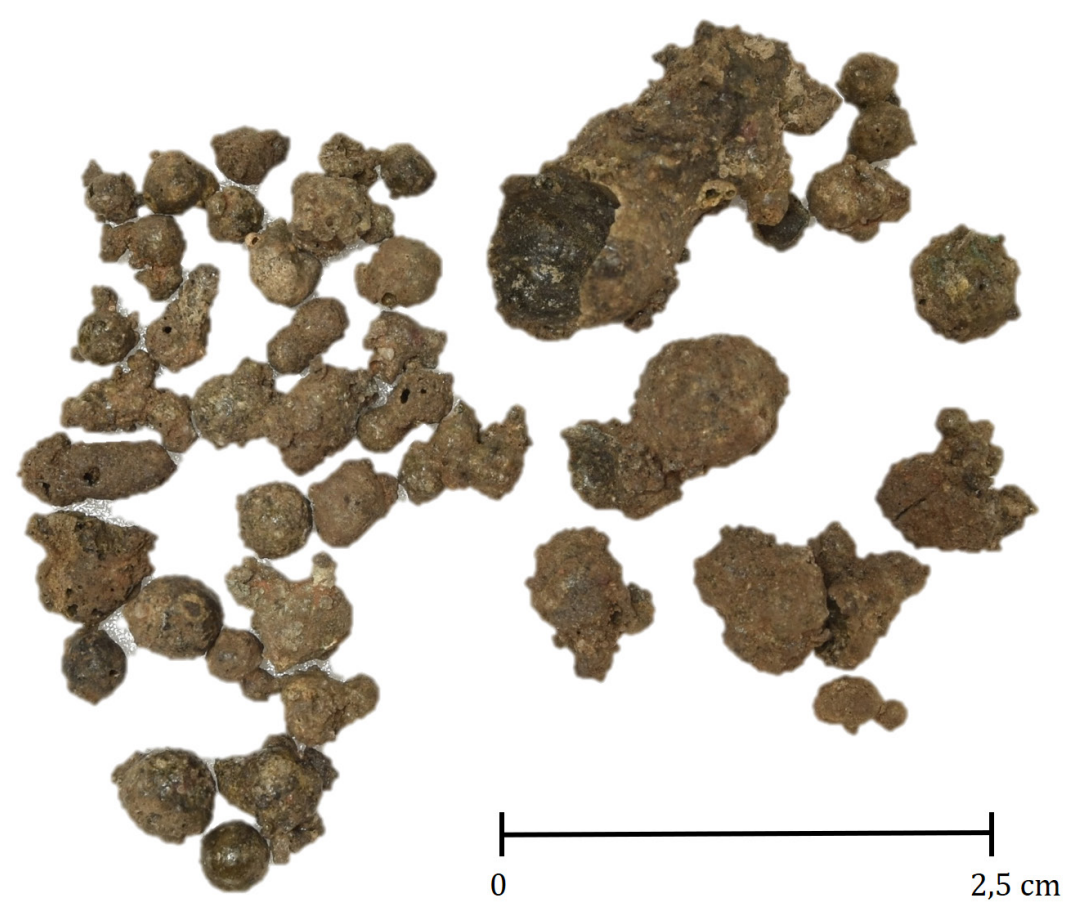

Figura 3. Fotografía de las cuentas de pasta vítrea documentadas en el interior de la caja (fotografía: Ana M. Herranz, @Construyendo Tarteso).

\subsection{Descripción de las placas}

Placa 1 o sur: el motivo central de esta placa es una procesión de tres peces que miran hacia el lado izquierdo. La escena está enmarcada por dos líneas paralelas que delimitan el espacio expositivo, una por encima y otra por debajo de los peces. La separación entre cada uno de los peces está marcada por cuatro líneas paralelas que delimitan cada uno de los espacios en los que se insertan sendos ejemplares. Aunque su diseño es bastante esquemático, se han señalado su boca, los orificios nasales y las branquias. Mientras, tanto los ojos como las escamas se han ejecutado mediante un troquelado de sección circular con una perforación más profunda en el centro. Finalmente, sus colas presentan sección triangular y su interior se ha representado mediante la sucesión de cuatro líneas paralelas en sentido horizontal.

Dimensiones: $18,8 \mathrm{~cm}$ de largo por 2,3/1,7 cm de ancho y $0,3 \mathrm{~cm}$ de grosor. ${ }^{2}$

2. Las medidas del ancho de las placas corresponden en todos los casos a cada uno de sus extremos (izquierdo/ derecho), pues en ninguno de los ejemplares recuperados las placas son perfectamente rectangulares. La diferencia en la anchura que presenta cada extremo de las placas nos lleva a plantear la posibilidad de que la caja fuese de sección trapezoidal. 
Placa 2 u oeste: La escena representa un león devorando la pata de un posible cérvido o bovino mientras contempla ante sí el hundimiento de una embarcación. La escena ha sido representada del mismo modo que las naves descritas anteriormente; sin embargo, el hecho de que la nave se muestre inclinada nos lleva a pensar que se ha querido representar mientras se hundía. Frente al barco, el león en posición sedente ha sido representado con las fauces abiertas y los dientes señalados, devorando la pata de un herbívoro que por su pezuña pudiera ser identificado con un bovino o cérvido. Aunque la representación del león es esquemática, se distingue, además de la boca, la nariz y el ojo, del que incluso se ha marcado la ceja. La melena se ha diseñado a partir de líneas cruzadas y triángulos enmarcados en los espacios definidos por las líneas anteriormente descritas. En el interior de su lomo se han estampado cinco círculos con el mismo troquel que el empleado para la realización de las escamas de los peces presentes en la placa sur. Por último, en el extremo derecho de la placa se ha representado media flor de loto abierta, por lo que solo puede apreciarse medio pistilo, cuyo tallo se ha definido mediante el uso de pequeños triángulos.

Dimensiones: 10,2 cm de largo por 3/2,7/2,4 cm de ancho y 0,3 cm de grosor.

Placa 3 o norte: la escena se encuentra enmarcada por sendas líneas paralelas, una en la parte superior y otra en la inferior de los lados largos de la placa, mientras que tres líneas verticales acotan el extremo izquierdo, dejando el extremo contrario abierto. La escena de la placa norte está presidida por una procesión de tres barcos de casco alargado y aplustre recurvado, dibujados de manera muy esquemática, lo que no permite ahondar en su tipología. Los cascos de los barcos están decorados con dobles líneas en zigzag enmarcados, tanto en la parte superior como en la inferior, por dos líneas paralelas. Bajo las proas de las embarcaciones, la presencia de tres triángulos superpuestos parece aludir al oleaje generado por el paso de las embarcaciones, lo que da cierta movilidad a la representación. Así mismo, la disposición de las embarcaciones, una contigua a la siguiente, aporta profundidad a la representación. Por último, sobre la cubierta de las naves se ha representado una serie de rectángulos, nueve en el caso de las dos primeras embarcaciones y ocho para la tercera, que bien pudieran estar representando las portas de bogada, las portezuelas por las que asomaban los remos.

Dimensiones: 14,7 cm de largo por 2,7/2 cm de ancho y 0,2 cm de grosor.

Es la única placa que además conserva in situ uno de los clavos de marfil que debían unir las placas a la caja de madera. El clavo, de cabeza circular, tiene 0,7 cm de diámetro y $1,2 \mathrm{~cm}$ de largo.

Placa 4 o este: En esta escena aparece representado también un león, con las fauces abiertas, los dientes marcados y el hocico apuntado, devorando la pata de un cérvido o bovino que en este caso ha sido representada de perfil, pues además de la pezuña se ha dibujado el dedo trasero de la pata. Está también en posición sedente; sin embargo, el mal estado de conservación de la pieza impide ver con detalle la ejecución del 

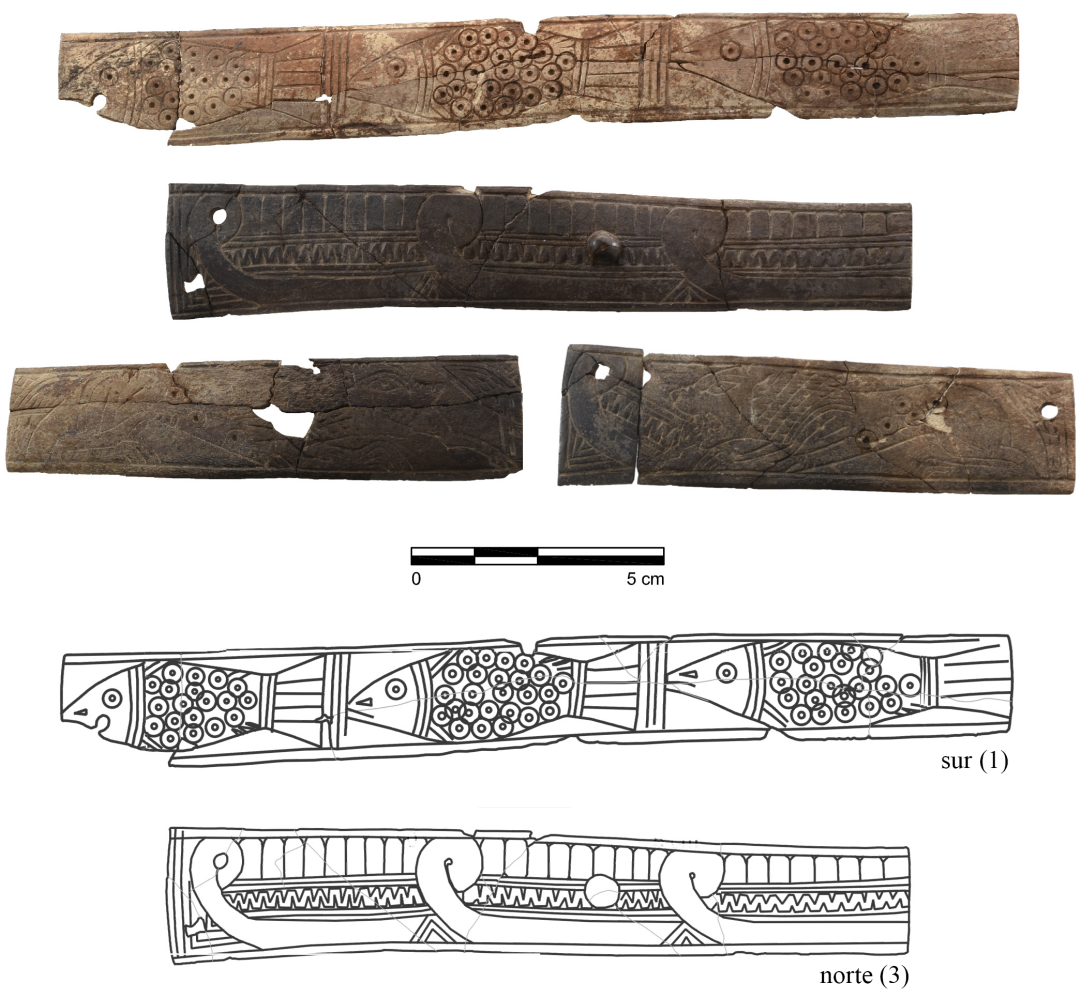

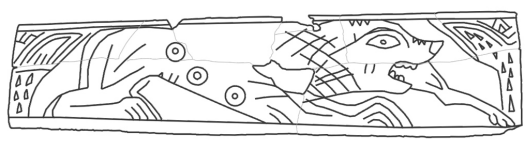

este (4)

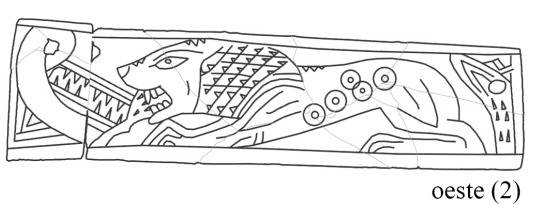

Figura 4. Fotografía y dibujo de las placas halladas en la estancia 100 del yacimiento de Casas del Turuñuelo (Guareña, Badajoz) (fotografías y dibujo: Esther Rodríguez González, CConstruyendo Tarteso).

cuerpo. Con el ojo de perfil y la ceja definida, la melena se ha representado mediante el trazado de líneas cruzadas, aunque en este caso no se observa la presencia de triángulos. Por su parte, en el lomo se conservan tres círculos troquelados como los que tenía el león de la placa anterior. En los extremos han sido representadas medias flores de loto abiertas que siguen el mismo esquema de la placa oeste, con los tallos definidos por pequeños triángulos y la mitad del pistilo.

Dimensiones: 10,1 cm de largo por 2,2/2,5 cm de ancho y 0,3 cm de grosor. A esta placa pertenece el segundo clavo de marfil recuperado durante la excavación; 
es también de cabeza circular y conserva unas dimensiones de 0,8 cm de diámetro por 1,4 cm de largo.

No cabe duda de que la iconografía que presentan las cuatro placas halladas en la estancia 100 de Casas del Turuñuelo es de clara influencia oriental. Además, dos de los motivos representados ofrecen cierta originalidad, pues la procesión de barcos documentada en la placa norte es hasta la fecha un motivo inédito en la eboraria orientalizante. Sin embargo, la placa con la procesión de peces, aunque rara, no es inédita, ya que conocemos un ejemplo dentro de la eboraria tartésica que podríamos considerar como su paralelo más cercano. Nos referimos al marfil de la necrópolis de Acebuchal (Carmona, Sevilla), donde parece conservarse un pez completo y parte de otros dos, por lo que bien podrían estar formando parte de una serie similar a la que aquí tratamos (Aubet, 1982: 56). Así mismo, este motivo iconográfico no es desconocido dentro del arte orientalizante, como puede comprobarse en la decoración de la bandeja de bronce del Gandul (Fernández Gómez, 1989; una revisión reciente en Gómez Peña, 2018) en cuyo fondo se representaron cuatro peces. Pero quizás el ejemplo más cercano y con el que la placa del Turuñuelo comparte más rasgos en común es con el plato de cerámica gris documentado en la bustum 86G/7bis de la necrópolis de Medellín (Almagro-Gorbea, 2004: 21-22, fig. 7). La decoración del interior del plato cuenta con una procesión de peces, tres en total, separados por "rosetas lobuladas» de ocho pétalos, que miran hacia la izquierda, un rasgo —además del número de peces representados-que la pieza de Medellín comparte con la del Turuñuelo.

El significado de estas representaciones resulta hasta el momento desconocida; sin embargo, han sido puestas en relación con un contexto funerario (Olmos, 2007-2008) y la alegoría del viaje al más allá (Almagro-Gorbea, 2004: 22); una lectura iconográfica que compartimos, si tenemos en cuenta el resto de motivos presentes en las placas del Turuñuelo: los barcos, el medio tantas veces aludido para llevar a cabo ese viaje al más allá (Escacena et al., 2007: 24), y los leones, identificados con la diosa Astarté, señora del inframundo (Gunter, 2009; Niemeier, 2014). Además, los leones constituyen un motivo recurrente en la eboraria tartésica, como queda patente en abundantes paralelos procedentes de necrópolis como la Cruz del Negro (Carmona, Sevilla), el Acebuchal (Carmona, Sevilla), el Bencarrón (Alcalá de Guadaira, Sevilla) o Medellín (Badajoz); un motivo que, en definitiva, tiene una fuerte representación en el mundo oriental, transmitida por todo el Mediterráneo (Le Meaux, 2010a: 49-53). Algo similar ocurre con las flores de loto, presentes en los extremos de dos de las placas, abundantes dentro del denominado arte orientalizante y ampliamente extendidas en la industria del marfil y el hueso (Le Meaux, 2010a: 5-18).

De la lectura iconográfica de las placas pueden extraerse otras dos interpretaciones que posteriormente pondremos en relación con su proceso de fabricación. Así, el análisis integral de su iconografía nos permite observar la relación que guardan entre ellas, conformando en uno de los casos una escena, algo que ya ha sido documentado en otras 
producciones de la eboraria tartésica, caso de las placas localizadas en el Bencarrón (Le Meaux, 2006), donde puede realizarse una lectura continuada de ellas.

De ese modo, la escena presente en la placa norte parece continuar en la placa oeste, representando así una procesión de barcos que navega directa a las fauces abiertas de un león que se encuentra devorando la pata de un herbívoro. La primera embarcación de esta pequeña flota sería el barco grabado frente al león, el cual no respeta la horizontalidad de las tres embarcaciones de la placa mayor, sino que ha sido representado con cierta inclinación, lo que nos induce a pensar que la intención del artesano era representarlo mientras se hundía frente a la bestia. La hipótesis acerca de que se trata de una escena continua se ve reforzada si tenemos en cuenta que tanto la placa norte como la oeste no han sido rematadas en sus extremos derecho e izquierdo, respectivamente, con la misma decoración que la representadas en los otros extremos de las placas, de ahí que exista una intencionalidad en crear una lectura continua. La serie finalizaría con la presencia de una procesión de peces que, sin duda, encaja a la perfección con los motivos presentes en la placa contraria, la procesión de barcos. De ese modo, la combinación de las cuatro piezas recoge una doble lectura que alude al mundo acuático y terrenal.

Otro elemento destacable en la decoración de las placas son las medias flores de loto representadas en ambos extremos de la placa este y en el extremo derecho de la oeste. Este tipo de juegos visuales son comunes en la eboraria fenica, caso de algún ejemplo documentado en Samaria (Naeh, 2015: 90, fig. 10) y en la tartésica, cuyo paralelo más cercano lo encontramos en las patas de la arqueta de marfil de Cancho Roano (Maluquer de Motes, 1983: 90, fig. 34).

Se trata de un juego visual en el que se representa media flor de loto en el extremo de una placa y otra media en el extremo de la placa contigua, de tal modo que al observar el objeto desde una de sus esquinas la flor pueda contemplarse completa. Lamentablemente, esta conexión visual no se cumple en el caso de las placas del Turuñuelo, pues estas representaciones se localizan en dos extremos opuestos de la caja.

Aunque alejado en el espacio, pero no el tiempo, el paralelo que más se acerca a las escenas documentadas en las placas de Casas del Turuñuelo es la iconografía presente en las acuñaciones de las ciudades fenicias de Biblos, Sidón y Arado, concretamente los séqueles emitidos entre los siglos VI y IV aC, monedas en cuyos anversos abundan las representaciones de embarcaciones (Elayi y Elayi, 2014a). De las tres ciudades mencionadas, es el ejemplo de Biblos el que más se acerca a nuestro caso de estudio, no solo por las similitudes que el diseño de las naves guarda con las embarcaciones de las placas del Turuñuelo, sino por que en sus reversos se representan escenas en las que un león aparece devorando un toro o un cérvido; es decir, exactamente los mismos recursos iconográficos que los aparecidos en el conjunto de las placas objeto de estudio. No obstante, cabe reseñar que las representaciones náuticas de los anversos de las acuñaciones de Biblos, Sidón y Arados poseen un elemento en común, presente también en las placas del Turuñuelo: la plasmación de las olas, dibujadas mediante el trazado de una serie continua de triángulos que en ocasiones se representan con una línea simple o mediante varias líneas paralelas en zigzag, siempre bajo los cascos de las naves. 

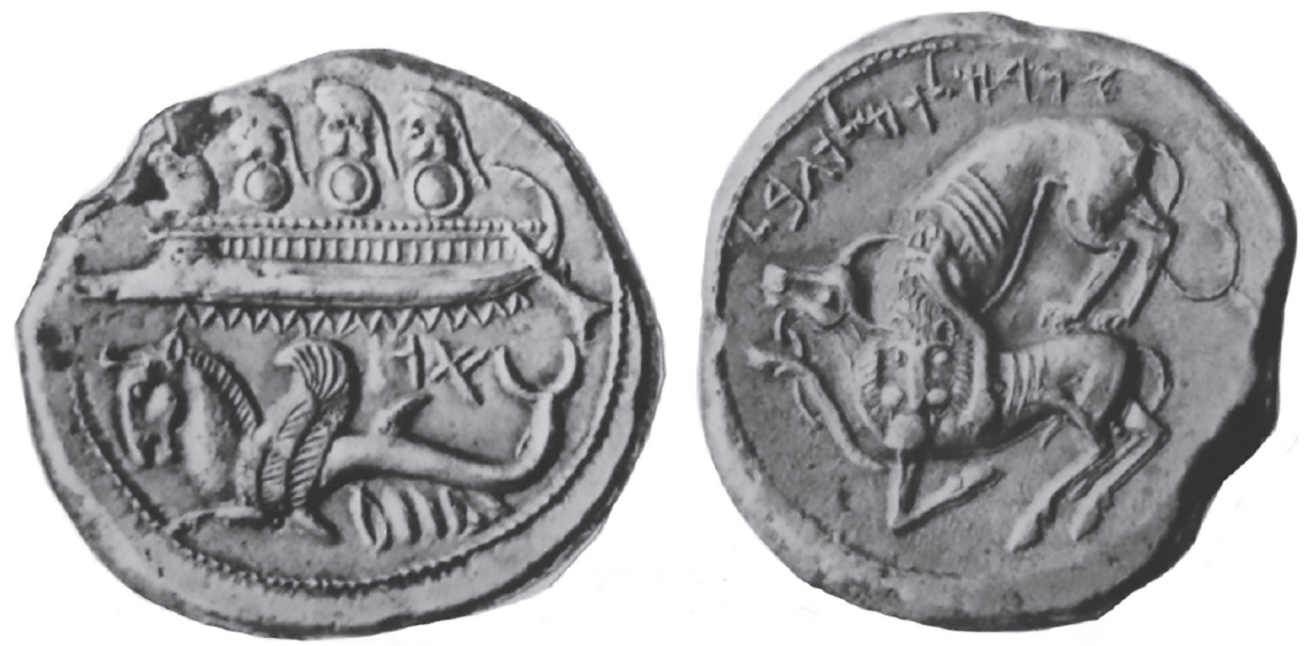

Figura 5. Séquel de Urimilk, Biblos (según Elayi y Elayi, 2014b: 375, fig. 793).

En lo que respecta a la representación de las naves, las aparecidas en las acuñaciones de Biblos e interpretadas como galeras (Elayi y Elayi, 2014b: 27) son las que guardan mayores similitudes con las embarcaciones aparecidas en la placa de marfil del Turuñuelo (fig. 5). Su diseño ha ido evolucionando a lo largo de las diferentes series acuñadas, donde las escenas han ido ganando en complejidad; sin embargo, el motivo de la escena principal es siempre el mismo, variando únicamente los prótomos de las naves, en unas ocasiones cabezas de león y, en otras, de bovino. Por su parte, las naves son de casco alargado y bajo ellas se representan las olas mediante la ejecución de una serie de triángulos contiguos; mientras, sobre el casco se dibujan las portas a través de las cuales asomaban los remos, no representados en el caso de las acuñaciones de Biblos, pero sí en las de Sidón. Sobre las portas, una serie de pequeños puntos han sido interpretados como escudos (Elayi y Elayi, 2014b: 28), sobre los cuales se representaron tres guerreros portando un escudo y ataviados con un casco corintio.

Resulta complicado saber si los motivos presentes en las placas de Casas del Turuñuelo están realmente imitando la misma decoración que la documentada en las monedas acuñadas en la ciudad fenicia de Biblos; sin embargo, hasta la fecha, esas monedas constituyen la analogía iconográfica más cercana, pues aunque el motivo del león y las flores de loto son recurrentes en la artesanía fenicia y tartesia, no ocurre así con las embarcaciones, ya que el marfil del Turuñuelo es el primer ejemplo de este tipo de representaciones en cualquier tipo de soporte. Por todo ello, las placas objeto de estudio son un claro ejemplo de la influencia del arte oriental en las producciones de Occidente, fruto de un comercio mediterráneo que favoreció la llegada de productos manufacturados que posteriormente se comenzaron a producir en talleres occidentales, como más adelante veremos. 


\section{Resultados de los análisis}

Las cuatro placas y los dos clavos recuperados durante las labores de excavación han sido sometidos a dos tipos de análisis. La primera fase ha consistido en una descripción macroscópica en el laboratorio del Instituto de Arqueología (CSIC-Junta de Extremadura) a partir de una lupa estereoscópica Leica EZ4D. Para la adquisición de las imágenes hemos empleado el software Leica LAS EZ. Esta primera observación ha permitido clasificar las placas atendiendo a la materia prima utilizada, para lo que se ha empleado la metodología de Espionza y Mann (1992), consistente en la detección y estudio de los patrones de lamellae que conforman el marfil y los canales haversianos propios de los materiales óseos, con la finalidad de hacer una primera distinción que permitiese cruzar los datos obtenidos en los posteriores análisis espectrográficos. Así mismo, se estableció la presencia o no de líneas de Scherenger, propias de los proboscídeos, para hacer una primera diferenciación entre el marfil del elefante y el resto de tipos.

Esta primera fase de trabajo nos permitió distinguir la presencia de dos tipos de materia prima para la fabricación de las placas y los clavos de la caja. Con el objetivo de corroborar los resultados ópticos, se contrastaron con los obtenidos en un análisis espectrográfico de infrarrojos realizados en el Instituto de Ciencias de los Materiales (CSIC-Universidad de Sevilla). El instrumental empleado para la realización de los análisis ha sido un Jasco FT7IR-6200 IRT-5000 y el método empleado, la reflectancia atenuada con el objeto de asegurar la integridad de las piezas, al no requerir este método preparación alguna de la muestra. El espectro analizado está comprendido entre los 600 y los $4000 \mathrm{~cm}^{-1}$, cubriendo ambas fases —orgánica e inorgánica- del material. Este espectro comprende todas las áreas que ofrece una diagnosis clara del tipo de marfil, así como una información consistente del contenido orgánico (colágeno). Los espectros obtenidos se han comparado con la colección de muestras de referencia del INCENTIVS de la Universidad JohannesGutenberg de Maguncia, así como con un elemento que previamente ha sido identificado como marfil de hipopótamo.

Los clavos, asociados a las placas este y norte, fueron analizados macroscópicamente, sin que los resultados fueran los esperados, pues ambas piezas se han visto afectadas por un proceso de combustión muy agresivo como resultado del incendio al que fue sometido el edificio antes de su amortización, a lo que se suma el tratamiento de pulimentado con el que fueron acabados, lo que hace que su superficie sea muy regular. Los análisis FTIR han permitido confirmar que ambos fueron realizados con marfil de hipopótamo (fig. 6), si bien el espectro del clavo norte presenta claras diferencias con respecto al estándar obtenido por el INCENTIVS (Banerjee et al., 2017) en la banda entre 1200 y $1700 \mathrm{~cm}^{-1}$, unas diferencias derivadas del proceso de combustión. Al margen de este dato, en torno al $872 \mathrm{~cm}^{-1}$ se encuentra el pico característico de la mayor mineralización del marfil de hipopótamo.

Por su parte, el clavo este no ofrece ninguna duda, pues el espectro presenta una mayor intensidad del pico principal del fosfato en torno a los $1000 \mathrm{~cm}^{-1}$, que contribuye a su identificación con el marfil de hipopótamo. Así mismo, el pico en torno al $870 \mathrm{~cm}^{-1}$, 


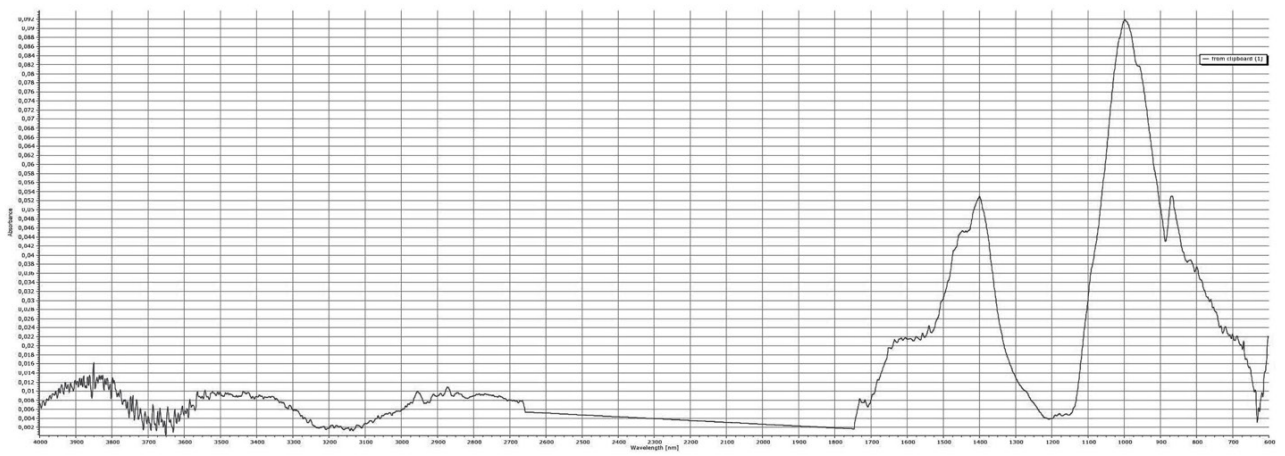

norte

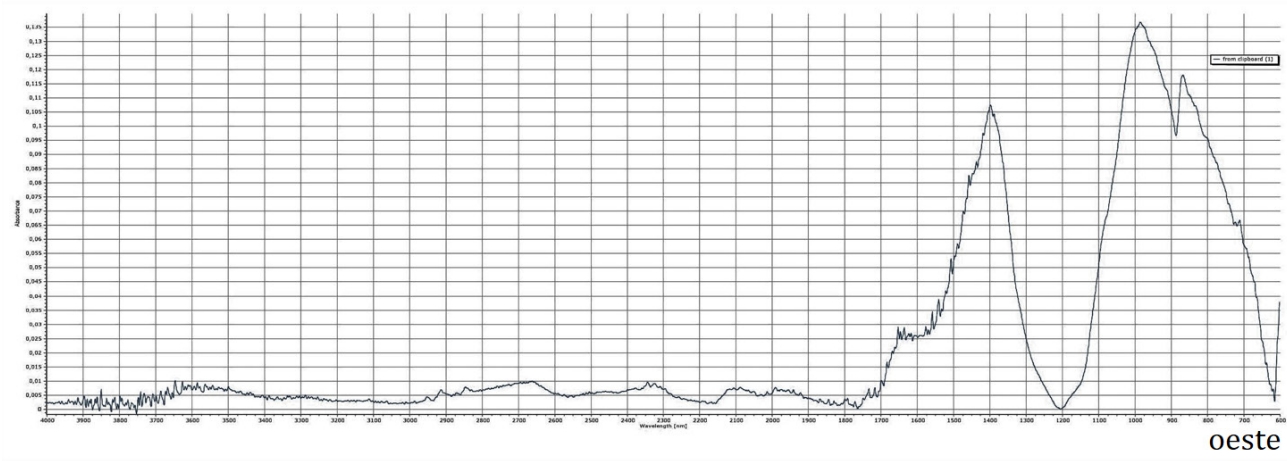

Figura 6. Espectros resultado del análisis FTIR de los clavos asociados a las placas norte y este (diseño: José Miguel Morillo, (C) Construyendo Tarteso).

característico del hipopótamo, está también presente, aunque se ve sobredimensionado debido a que el principal pico del fosfato aparece truncado por la combustión. La fase orgánica, a partir de $1700 \mathrm{~cm}^{-1}$, resulta inapreciable, a causa de la desaparición del colágeno como consecuencia de las altas temperaturas a las que fue sometida la pieza.

Mayor interés presenta los resultados obtenidos en los análisis FTIR realizados a las cuatro placas, al haber podido confirmar el uso de dos materias primas diferentes cuyas procedencias serán analizada más adelante: el hueso y el marfil. Los análisis macroscópicos realizados en las placas oeste, sur y este ya permitieron determinar que se trataban de producciones de hueso, gracias a la presencia de los canales haversianos que se observan tanto en las fracturas como en los reversos de las placas, la única zona no trabajada ni pulimentada, por estar destinada a ir adherida a la caja de madera (fig. 7). Esta caracterización ha sido corroborada en todos los casos a partir de los resultados de los análisis FTIR, donde la señal de fosfato es significativamente menor que en las piezas fabricadas en marfil, a excepción de la placa sur, y donde la presencia de un pico de fosfato de similar intensidad al del marfil hace que nos inclinemos por la selección de un hueso de alto nivel de densidad y dureza por 


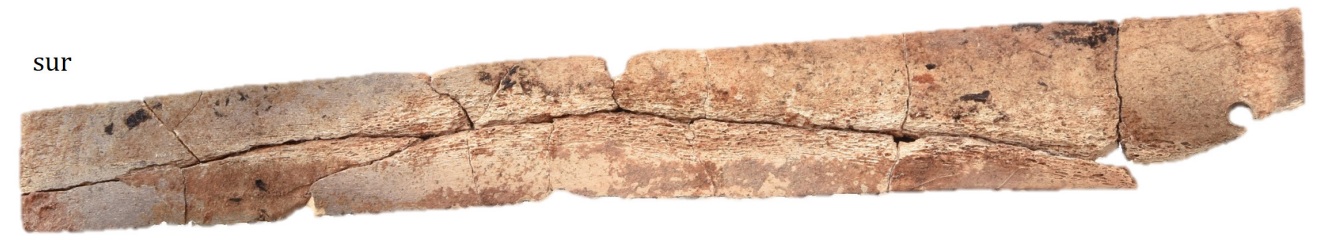

este

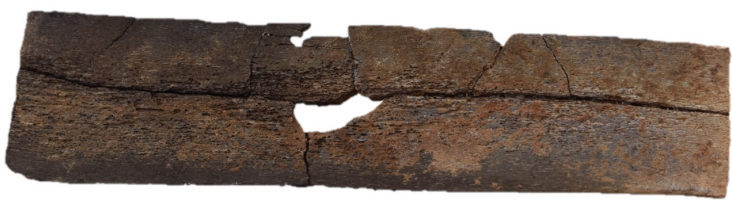

oeste
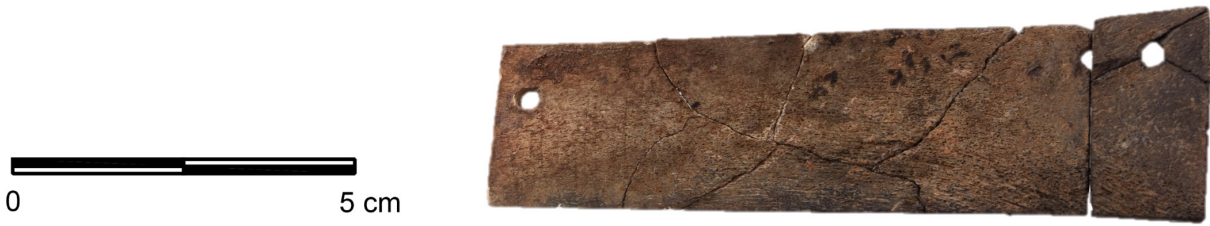

Figura 7. Fotografías de los reversos de las placas sur, este y oeste donde se aprecia la presencia de canales haversianos (fotografía y montaje: Ana M. Herranz, (C) Construyendo Tarteso).

parte de los artesanos. Determinar la especie animal de la que proceden los huesos empleados es una labor que solo los análisis de ADN podrían determinar; unos análisis de carácter destructivo que, dada la mala conservación de la pieza, resultarían inútiles.

En lo que a la placa norte respecta, los resultados ópticos y los análisis han permitido corroborar que, al igual que los clavos, fue fabricada con dentina de hipopótamo (fig. 8).

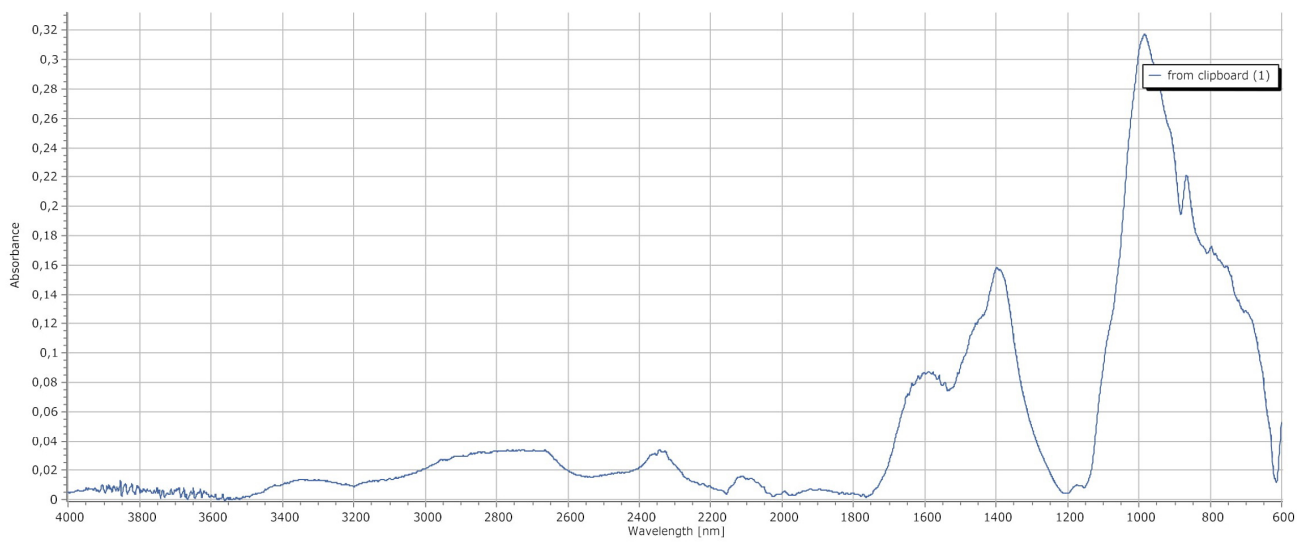

Figura 8. Espectro resultado del análisis FTIR de la placa norte (diseño: José Miguel Morillo, CConstruyendo Tarteso). 
Así, el espectro muestra la señal del fosfato en torno a los $1000 \mathrm{~cm}^{-1}$, así como el pico de mineralización propio del marfil de hipopótamo en torno a los 850-875 $\mathrm{cm}^{-1}$. La fase inorgánica que continua hasta $1700 \mathrm{~cm}^{-1}$ muestra la misma conformación que la de los clavos, diferenciada del estándar del marfil de hipopótamo debido, como decíamos, a la pérdida de colágeno producida por la combustión. En cuanto a la fase orgánica, aunque en mucha menor intensidad debido a la mencionada pérdida de colágeno, mantiene bandas características del marfil de hipopótamo entre 2000 y $2400 \mathrm{~cm}^{-1}$ y 2600 y $3000 \mathrm{~cm}^{-1}$.

\section{La restauración como herramienta de estudio}

Como es sabido, el hueso y el marfil conforman, desde época prehistórica, un tipo de artefacto de diversa funcionalidad que se documenta de manera usual en los yacimientos. Su supervivencia en el medio arqueológico depende no solo de una serie de factores intrínsecos como el tipo de material, su tecnología y los tratamientos aplicados o su vida útil entre otros, sino de factores extrínsecos relativos a las condiciones del medio arqueológico, tales como el tipo de sedimento, la presión, la porosidad y compactación, el pH del suelo, la presencia de humedad, los fenómenos de hidrólisis, etc., dependiendo los procesos de alteración en gran medida de la interacción entre los agentes ambientales y los de su composición fisicoquímica, de ahí que sea imprescindible la identificación de sus elementos constitutivos para la determinación de las alteraciones y del tratamiento a emplear. En este sentido, los resultados obtenidos de la espectroscopia infrarroja por transformación de Fourier (FTIR) han resultado de gran utilidad, al poder determinar a partir de ellos el tratamiento a emplear, una información que ha resultado relevante para establecer los criterios de conservación de las piezas.

En este caso, tanto el marfil como el hueso, a pesar de tener una fracción inorgánica que les aporta fuerza y rigidez, compuesta por fosfato, fluoruro y carbonato cálcico (García y Flos, 2008: 28), también poseen otra fracción de carácter orgánico por la presencia de colágeno, cuyas fibras forman una matriz donde se fijan las sustancias minerales. Si bien al cabo de cierto tiempo el componente orgánico acaba por desaparecer, quedando relegado el material casi a sus componentes minerales (Egocheaga, 1989: 76), un medio ácido pudiera llegar a causar un proceso de descalcificación notable, mermando su rigidez y resistencia mecánica, características que se conservarían, sin embargo, en un medio de alta basicidad como en el presente caso, en el que no obstante el hueso termina por volverse frágil y friable al descomponerse el resto de sus componentes orgánicos (Acevedo y Vergara, 2009: 126; Tiley-Nel y Antonites, 2015: 8).

Existe multitud de factores que pueden influir en la degradación del hueso y del marfil, siendo no menos importantes los asociados al momento de la excavación (Cho y Chinchilla, 2008: 86) y durante el paso repentino del medio arqueológico al aéreo, cuando, en tanto que son materiales higroscópicos que sufren cambios dimensionales en función 
de la absorción o expulsión de humedad (Rosas et al., 2005: 71), inician un proceso de reequilibrio con el nuevo medio que, en ocasiones, ante la falta de medidas preventivas, puede implicar un deterioro irreversible o su completa desaparición. Precisamente es esta peligrosa cualidad la que también contribuye a que el marfil y el hueso se sitúen dentro del grupo de materiales arqueológicos orgánicos, al ser esta una característica común de todos ellos (Corrado y Pulga, 2010: 27).

En el caso de las placas de la estancia 100 del yacimiento de Casas del Turuñuelo, las labores de restauración y limpieza de las piezas tuvieron una relevancia total, en tanto en cuanto eran necesarias para poder analizar toda su iconografía, perdida en muchos casos por la presencia de depósitos de carbonato cálcico. Ante la irregularidad en la distribución y el tipo de carbonatos, se ha procurado llevar a cabo una eliminación controlada al objeto de obtener una limpieza homogénea. Las tierras carbonatadas más gruesas han sido rebajadas al nivel de las más finas, pero muy adheridas, que han establecido el límite de la limpieza por su difícil remoción, la cual implicaba el desprendimiento del mismo material óseo o ebúrneo (fig. 9a). La limpieza de las placas se ha llevado a cabo mediante métodos mecánicos y químicos, combinando la aplicación de alcohol y la abrasión con palo de naranja sobre la superficie de las concreciones.

Gracias a la intervención realizada, que será presentada próximamente en un trabajo más detallado dedicado a la metodología empleada en la restauración de las placas, no solo se ha conseguido dotar las piezas de una estabilidad estructural y garantizar su conservación para el futuro, sino también la restitución de su unidad potencial y legibilidad, especialmente en cuanto a la documentación e interpretación de la iconografía incisa se refiere (fig. 9b). Uno de los elementos de interés detectados gracias a las labores de limpieza y restauración de las placas son las incisiones en zigzag presentes en el reverso de la placa norte (fig. 10). Aunque su funcionalidad no está del todo clara, pues la presencia de este tipo de marcas en las producciones occidentales no ha sido nunca abordada, en esta ocasión han sido interpretadas como un mecanismo para favorecer la adhesión de la placa a la caja de madera. Para ello posiblemente se emplease algún tipo de resina que favoreciese el adhesivo; sin embargo, no ha quedado resto alguno de ella. A este respecto, cabe señalar cómo durante las labores de restauración de la placa este pudo detectarse, dentro de los canales haversianos, un conjunto de depósitos amarillentos muy brillantes (fig. 11) que bien pudieran estar en relación con la presencia de resinas derretidas por las altas temperaturas del incendio o, por el contrario, tratarse de restos de oro procedentes de la decoración de las placas, una hipótesis plausible si tenemos en cuenta que dentro de la misma estancia se localizó otra placa de marfil exenta que contaba con este tipo de decoración en su borde (Rodríguez González y Celestino, 2017: 190, fig. 10b).

En las placas que decoran la caja de la estancia 100 del Turuñuelo estas marcas solo están presenten en la fabricada con marfil de hipopótamo, permaneciendo ausentes de las placas realizadas en material óseo. Posiblemente esto se deba a que en los casos en los que se empleó el hueso los reversos cuentan ya con cierta rugosidad proporcionada por los canales haversianos, lo que facilita su adherencia, mientras que la placa de marfil, de 

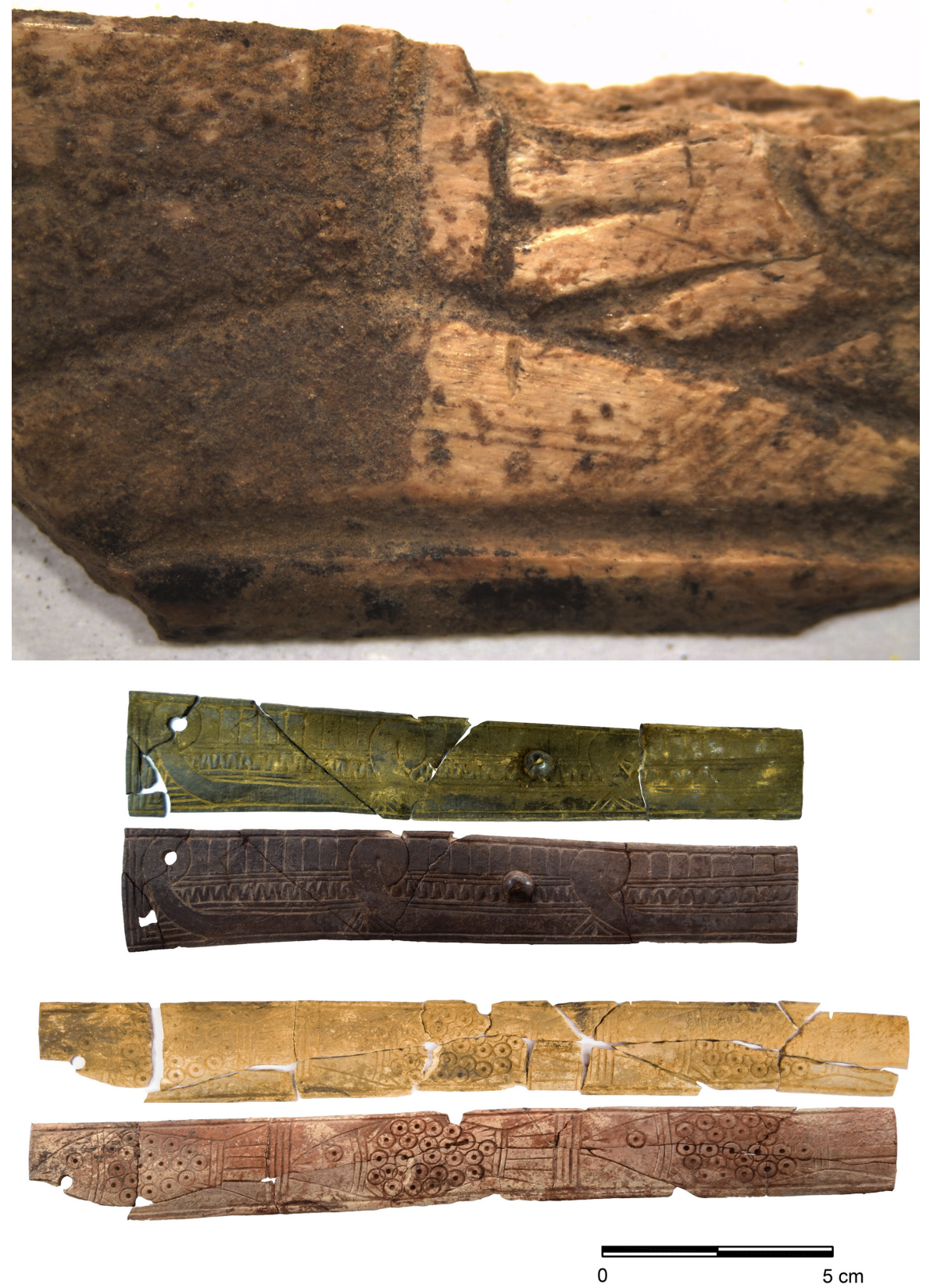

Figura 9. A) Fotografía de detalle de un fragmento de la placa sur donde puede apreciarse la labor de limpieza y restauración de la pieza (escala: 8x). B) Fotografía de las placas norte y sur antes y después de su restauración (fotografía y montaje: Ana M. Herranz, (C) Construyendo Tarteso). 

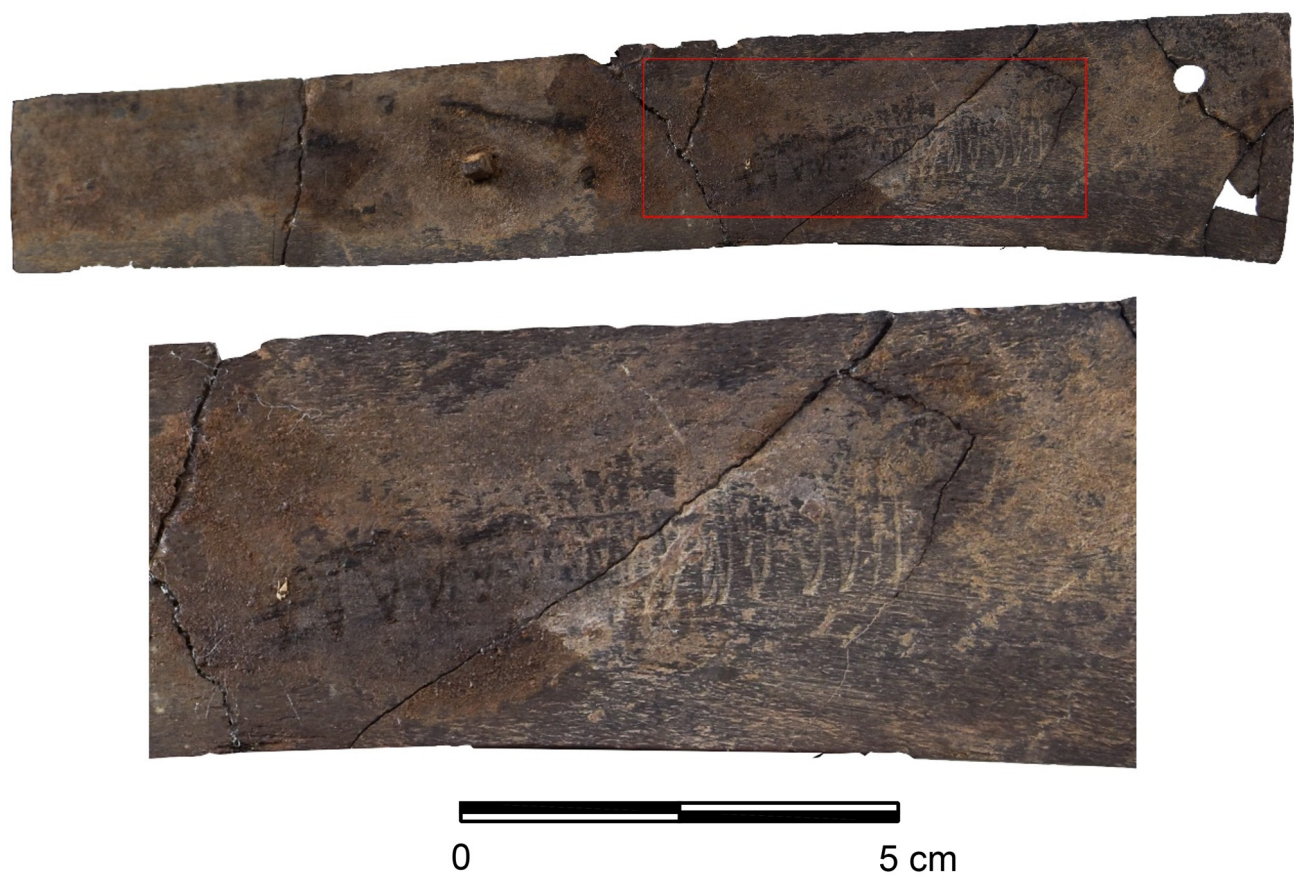

Figura 10. Fotografía de detalle de las líneas incisas en zigzag presentes en el reverso de la placa norte (fotografía y montaje: Ana M. Herranz, @Construyendo Tarteso).

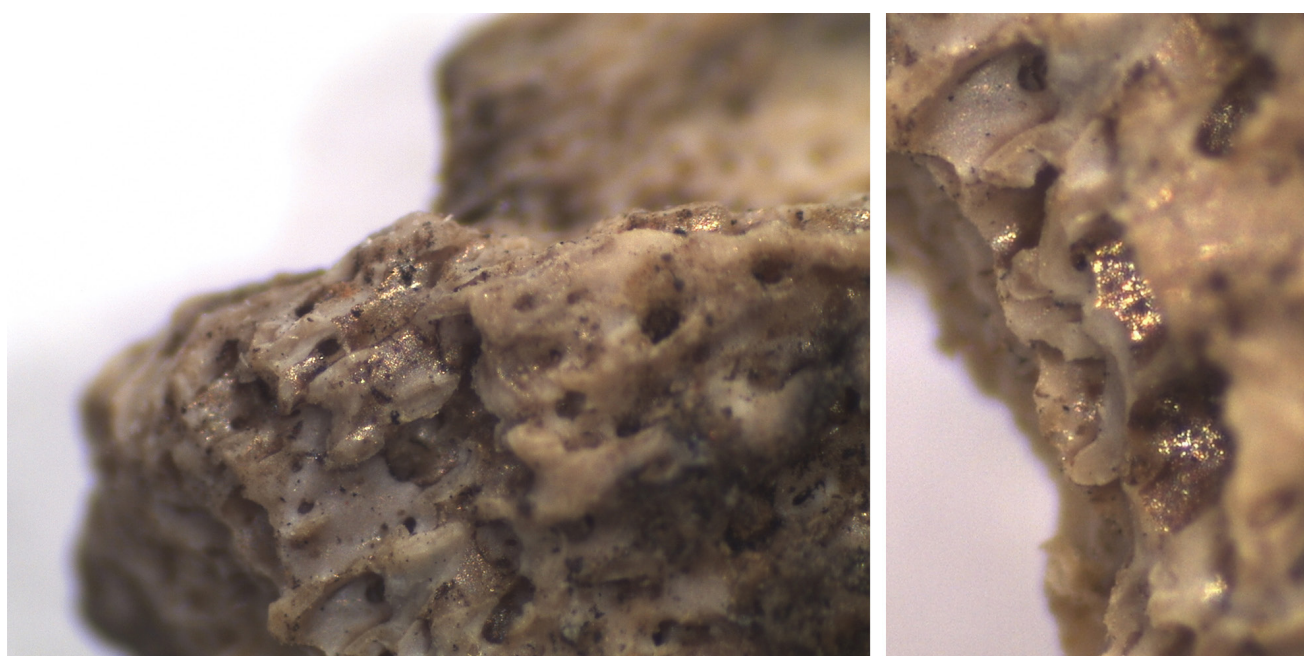

Figura 11. Fotografía de detalle de los depósitos presentes en los canales haversianos de la placa este (escala: 35x) (fotografía y montaje: Ana M. Herranz, (OConstruyendo Tarteso). 

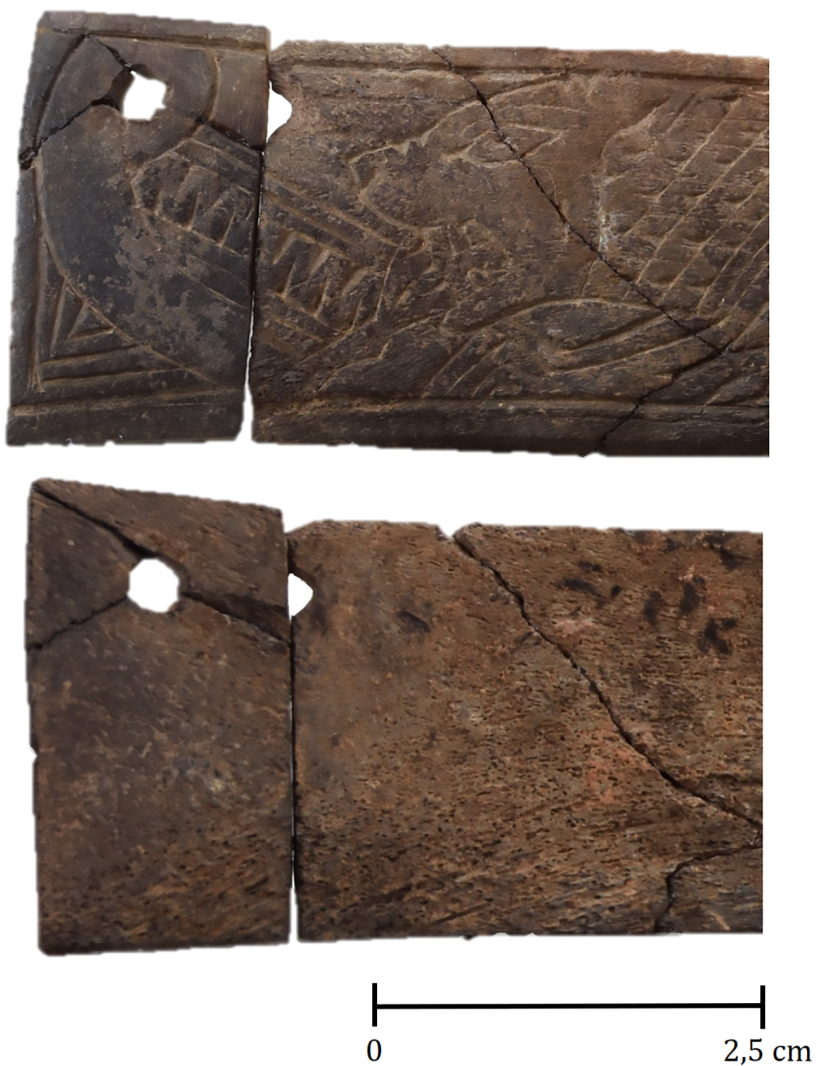

Figura 12. Fotografía de detalle del anverso y el reverso del extremo izquierdo de la placa oeste donde se aprecia la unión entre ambos fragmentos (fotografía y diseño: Ana M. Herranz, @CConstruyendo Tarteso).

superficie lisa al tratarse de un material denso que posteriormente ha sido pulimentado, necesita de esas marcas para mejorar su adhesión a una superficie plana (fig. 7).

Así mismo, los trabajos de restauración han sido fundamentales para comprender el proceso de preparación de las placas y su posterior decoración, una técnica que hemos conseguido reconstruir a partir del análisis de la placa oeste, fracturada en dos partes durante su proceso de fabricación, justo en el punto que separa la representación del barco y el león. La fractura fue provocada por la ejecución de una perforación para la inserción de uno de los clavos de sujeción de la placa. La fractura obligó a regularizar las caras fracturadas, de ahí la ligera diferencia detectada en la anchura de ambos fragmentos. Así, la placa se reparó para recibir posteriormente la decoración, un dato que puede observarse por la coincidencia en ambos fragmentos de los trazados de la decoración y de los canales haversianos presentes en el reverso de la placa (fig. 12), lo cual nos lleva a 
suponer un mismo proceso de producción para la fabricación de cada una de las placas, en el que los soportes fueron preparados antes de recibir la decoración, e incluso que la placa oeste se realizó con anterioridad a la este, pues posiblemente por la fractura que la placa sufrió durante su perforación se decidió no agujerear la placa contraria, donde cabe suponer la presencia de una única perforación en su parte central, justo la única no conservada.

Sin embargo, la pregunta más compleja de responder deriva del uso de dos tipos de materias primas. De ese modo, ¿a qué se debe la presencia de una placa fabricada con marfil de hipopótamo, al igual que los clavos, y otras tres fabricadas en hueso?

\section{Talleres y artesanos: nuevas lecturas a través del estudio de las placas de la estancia 100 de Casas del Turuñuelo}

A pesar de que los hallazgos de marfil son característicos dentro del horizonte tartesio, son escasos los estudios que abordan sus áreas de distribución, su técnica de fabricación $\mathrm{y}$, sobre todo, el material con el que fueron fabricados, frente a los abundantes estudios que analizan su iconografía (Almagro-Gorbea, 2008; Le Meaux, 2010a; 2010b). Así, son casi inexistentes los trabajos que abordan el estudio del comercio de marfil fenicio (Martín Ruiz, 2011), por no hacer alusión a la ausencia de analíticas que permitan caracterizar las especies empleadas y su procedencia.

En origen, los marfiles del Bajo Guadalquivir fueron incluidos dentro de las producciones fenicias occidentales (Aubet, 1979; 1980; 1982); sin embargo, la cronología que presentan estas piezas, cuya producción y uso se generaliza en los siglos VIII-VI aC, nos obliga a desechar su clasificación como fenicios para comenzar a denominarlos tartésicos, un concepto ya aceptado dentro de la comunidad científica (Aubet, 2008: 290; Torres, 2000: 259; Le Meaux, 2005: 1128).

Un problema recurrente a la hora de estudiar la eboraria tartésicos es la localización de sus talleres de producción, pues hasta la fecha no se han recogido evidencias de la existencia de un taller de eboraria en ningún asentamiento fenicio (Martín Ruiz, 2011: 89). En los primeros trabajos sobre estos marfiles se consideró la existencia de un único taller peninsular posiblemente localizado en las proximidades de una de las principales colonias fenicias de Occidente, principalmente Gadir, o bien en las tierras del interior, caso de Carmona, de cuya necrópolis de la Cruz Negro procede una de las principales colecciones de marfiles tartésicos conocida hasta la fecha (Aubet, 1980: 275); sin embargo, en la actualidad se valora la existencia de varios talleres e incluso la posibilidad de que existiesen obradores itinerantes que realizaran encargos a medida (Aubet, 2008: 294; Almagro-Gorbea, 2008: 495 y ss). 
La presencia de marfil en bruto en algunos yacimientos del Bajo Guadalquivir ha llevado a plantear la existencia de talleres en los asentamientos occidentales. Es el caso de los hallazgos realizados en las excavaciones de la calle Méndez Núñez-plaza de las Monjas de Huelva, donde la existencia de restos de talla y marfiles a medio trabajar ha permitido defender tanto la presencia de un taller de eboraria dentro de este emporio precolonial, que ha sido fechado entre los siglos x y vIII aC (González de Canales et al., 2004: 163), como la existencia de unas rutas de comercio mediterráneo; un comercio que, por otra parte, comienza a ganar fuerza tras el hallazgo de las defensas de marfil presentes en el pecio del Bajo de la Campana (Mederos y Ruiz Cabrero, 2004).

Un caso de estudio más complejo de analizar es del trozo de marfil en bruto recuperado de las excavaciones de Cancho Roano (Zalamea de la Serena, Badajoz) (Celestino, 1997: 364), localizado en las tierras del interior. La posible existencia de un taller de fabricación de marfiles en este yacimiento tartésico resulta más difícil de justificar, pues entre las evidencias arqueológicas no se documentaron restos de talla o herramientas relacionadas con su fabricación; sin embargo, no sería extraño que existiese marfil en bruto destinado a la reparación de piezas ya manufacturadas que por el uso y el paso del tiempo sufriesen algún tipo de deterioro, del mismo modo que en muchos enclaves existen espacios o pequeños talleres para la reparación de cerámicas u objetos de metal de uso cotidiano.

La ausencia de análisis en la mayor parte de los conjuntos de marfiles conocidos complica la caracterización de sus producciones, así como la demarcación de las áreas geográficas de procedencia. El hallazgo del pecio de Bajo de la Campana, así como los análisis realizados a un conjunto de piezas de marfil procedente de la necrópolis de Medellín (Almagro-Gorbea, 2008; Le Meaux, 2010b: 113), muestran la mayor difusión del empleo de marfil de elefante procedente tanto de Asia Menor como de África, aunque resulta lógico pensar que las producciones peninsulares están realizadas con marfiles procedentes de este último continente (Martín Ruiz, 2011: 86).

Mucho más complicada es la caracterización geográfica del marfil de hipopótamo. Hasta la fecha solo se ha podido determinar el origen de uno de los fragmentos de marfil de hipopótamo documentado en Huelva, procedente del área palestina (Marzoli et al., 2016: 124). Así mismo, un reciente hallazgo en las excavaciones del enclave fenicio de Útica (Túnez) (Banerjee et al., 2017) ha permitido documentar la existencia de un fragmento de dentina de hipopótamo en bruto sobre el que se conserva un epígrafe en caracteres fenicios. Aunque no se han realizado análisis para conocer la procedencia de la materia prima, lo cierto es que la presencia de esta pieza en el yacimiento tunecino abre la posibilidad de que también exista un comercio del marfil de hipopótamo procedente de la región del África central y Egipto (Schuhmacher, 2016); con todo, dado que la presencia de hipopótamo entre los siglos x y vIII aC sigue atestiguada en el Levante del Mediterráneo, los investigadores encargados del estudio de la pieza tunecina se inclinan por pensar que esta materia prima procede del comercio fenicio (Banerjee et al., 2017: 98-99). Finalmente, junto al fragmento localizado en Útica y los procedentes del solar de la ciudad de Huelva, la última evidencia que tenemos sobre la presencia de marfil de hipopótamo en el sur de 
la Península Ibérica procede del yacimiento fenicio de la Rebanadilla, en Málaga (Marzoli et al., 2016).

La antigüedad que presentan los tres casos de estudio, fechados entre los siglos $\mathrm{X}$ y VIII aC, no permite encajar el hallazgo de Casas del Turuñuelo dentro de un mismo contexto comercial y cultural, pues, si bien la pieza del yacimiento extremeño pudiera catalogarse como una reliquia guardada dentro del edificio y fecharla así entre los siglos VII-VI aC, su técnica e iconografía son claramente tartésicas, aunque la materia prima sea una consecuencia del comercio fenicio.

Resulta complejo deducir por qué las placas que decoraban la caja de la estancia 100 del Turuñuelo fueron fabricadas empleando dos materias primas diferentes. A este respecto, nos inclinamos por pensar que, en origen, las cuatro placas y los clavos estaban fabricados con marfil de hipopótamo. El deterioro de las placas llevó a sustituirlas por nuevos ejemplares realizados en hueso sobre los que se copiaron los mismos motivos iconográficos que había en las placas de origen. La ausencia de marfil en bruto llevaría al artesano a sustituir el soporte por hueso de gran densidad que, una vez pulido, bien pudiera emular el resultado conseguido con el marfil. De hecho, la presencia de hueso y marfil en los conjuntos tartésicos no es exclusiva del yacimiento de Casas del Turuñuelo. La restauración de los marfiles recuperados en las excavaciones que Bonsor realizó en los Alcores, adquiridos por la Hispanic Society of America de Nueva York y hoy depositados en el Metropolitan Museum of Art, ha permitido constatar que las placas procedentes de Bencarrón y dos de las recuperadas en la necrópolis de la Cruz del Negro están fabricadas con hueso y no con marfil, como siempre se había dado por hecho (Lapérouse, 2008). Esto ha llevado a otros investigadores a suponer la existencia de un proceso de "copia» de marfil en hueso cuando este era necesario para reponer alguna de las piezas perdidas o deterioradas (Le Meaux, 2010b: 114-115). No obstante, solo la realización de una nutrida batería de análisis a conjuntos de marfiles procedentes de un mismo contexto permitirá afinar esta lectura.

La hipótesis más consistente es que las placas de Casas del Turuñuelo proceden de un taller occidental, principalmente por la técnica empleada para su ejecución, la incisión, una técnica bien conocida en los yacimientos tartésicos del Bajo Guadalquivir, donde predomina, frente al empleo del bulto redondo y el bajo relieve, presentes en los marfiles de procedencia oriental. No obstante, esta fórmula no parece ser exacta, pues hay todavía un enorme desconocimiento en torno a la procedencia de los artesanos encargados de la producción de estas manufacturas (Le Meaux, 2006). Sin embargo, en el yacimiento de Casas del Turuñuelo, concretamente en la estancia 100, contamos con producciones en las que se emplean ambas técnicas. En efecto, sobre el suelo de la sala, junto a las placas objeto de estudio en este trabajo, se halló un nuevo marfil en el que se representa una procesión de bovinos sedentes (Rodríguez González y Celestino, 2017: 190) que será objeto de un estudio pormenorizado, pues la pieza conserva tanto el oro que adorna sus bordes como el azul egipcio empleado en la decoración de los animales. La presencia de ambas técnicas puede ser una prueba de que existía tanto un comercio mediterráneo que 
abastecía la Península de marfiles, tanto en bruto como trabajados, como talleres locales donde se practicaba el grabado.

La llegada de contingentes de población fenicia a la península ibérica representó un cambio en el estilo iconográfico de los marfiles pues, como sabemos, el uso del marfil para la fabricación de objetos está atestiguada en la Península desde la prehistoria reciente (Luciáñez, 2018, con bibliografía). Es, pues, a partir de la colonización oriental cuando proliferan las escenas que imitan manufacturas de origen oriental, como así se desprende de la presencia de leones, aves exóticas o seres mitológicos, presentes en los marfiles documentados en el suroeste peninsular entre los siglos viII y v aC. La elección de los motivos decorativos, la mezcla de elementos y las variaciones o la simplificación de la técnica, así como la proliferación del uso del hueso frente al marfil, mucho más costoso de conseguir, hacen que la hipótesis que defiende la existencia de talleres occidentales gane fuerza. Pero ¿qué significado tienen estas representaciones dentro de la iconografía de Tarteso?

A excepción de las embarcaciones, ausentes en otros ejemplos de la eboraria fenicia y tartesia, el resto de motivos presentes en las placas de la estancia 100 de Casas del Turuñuelo son elementos recurrentes dentro de la iconografía oriental, en diversos tipos de soportes, caso de las flores de loto (Le Meaux, 2010a), así como los leones devorando su presa (Collins [ed.], 2002); sin embargo, todos ellos, incluidas las embarcaciones estrechamente relacionadas con las naves aparecidas en las acuñaciones de Biblos, Sidón y Arado, como ya hemos podido comprobar, son elementos originarios del extremo oriental del Mediterráneo, por lo que cabe preguntarse si su simbología tendría el mismo significado en Occidente o si, simplemente, se adquieren por su suntuosidad, al margen del lenguaje que transmiten. Algunos autores han apuntado la posibilidad de que las representaciones y escenas documentadas en las producciones occidentales carezcan por completo de contenido simbólico (Martín Ruiz, 2011: 93) y que se trate de reinterpretaciones realizadas desde el punto de vista local. Esta afirmación explicaría por qué en un mismo conjunto se combinan diferentes elementos que guardan escasa relación entre sí, algo recurrente en los distintos paneles que recubren cajas. Las placas documentadas en el yacimiento de Casas del Turuñuelo son un claro ejemplo de ello, pues se trata de producciones realizadas a partir del uso de dos materias primas distintas en las que, sin embargo, se emplea la misma técnica de la incisión, al tiempo que se documenta una escena completa en la que dos placas guardan una relación compositiva, frente al caso de las medias flores de loto presentes en los extremos de las placas oeste y este que rompen con la simetría de la composición.

Pero todavía podemos ir un paso más allá en la lectura iconográfica. Las producciones de marfiles en el mundo tartésico se fechan entre los siglos vIII y v aC, por lo que, si tenemos presentes estas cronologías, cabría preguntarse si durante cuatro siglos se están copiando motivos que desde las primeras producciones occidentales han perdido su simbolismo iconográfico. Se trata de una pregunta de difícil respuesta; sin embargo, cuesta creer que durante tanto tiempo se estén copiando unos mismos motivos sin reparar en su carga simbólica, más aún cuando muchos de ellos se están representando en otro tipo de soporte, caso de la toréutica, de los que sí se está realizando una lectura iconográfica 
y a los que sí se les está otorgando una carga comúnmente cultual. Quizá la respuesta más coherente a esta pregunta esté en el mercado al que iban destinadas estas piezas y su posterior uso. Los contextos en los que se documentan los marfiles o bien tienen una fuerte carga cultual o bien están directamente asociados a contextos funerarios, donde las piezas otorgan un significativo prestigio social al difunto. Es precisamente de las necrópolis de Bencarrón, la Cruz del Negro, Alcantarilla, la Joya, Medellín o la Angorrilla de donde proceden los mejores ejemplos de este tipo de artesanía, pues es en esos contextos cerrados donde presentan un mejor estado de conservación.

\section{Conclusiones}

El hallazgo de cuatro placas de hueso y marfil, así como dos de sus clavos, en el edificio de Casas del Turuñuelo, en el valle medio del Guadiana, junto a otros elementos de importación púnica y griega, nos marca la existencia de un intenso comercio mediterráneo que rápidamente se extenderá entre las élites occidentales más allá de los enclaves costeros. De ese modo, en los siglos vi y v aC están llegando a las tierras del interior peninsular productos manufacturados producidos en talleres tanto orientales como occidentales.

Las placas halladas en la estancia 100 de Casas del Turuñuelo guardan una significativa semejanza con las producciones del Bajo Guadalquivir, de donde sin duda proceden. Parece obvio que los primeros marfiles importados del Levante mediterráneo comenzaron a imitarse en Tarteso en fechas muy tempranas, respetando la iconografía oriental, pero introduciendo una nueva técnica de fabricación, la incisión, mucho más versátil de practicar sobre hueso, el elemento predominante cuando decae el comercio del marfil a través del Atlántico a partir del siglo vi aC. Aún estamos lejos de identificar la filiación de los primeros artesanos, así como de determinar si existe o no intencionalidad en la rica iconografía desplegada en los marfiles occidentales. Lo que sí parece claro es que hay una simplificación de la técnica, pues la incisión comienza a ganar terreno al bajo relieve o al bulto redondo. Así mismo, los escasos análisis macroscópicos realizados a varios de los conjuntos de piezas localizados en las necrópolis de los Alcores están permitiendo observar el predominio del uso del hueso frente al del marfil, posiblemente por que la llegada de marfil en bruto se fue reduciendo con el paso del tiempo hasta ser casi inexistente a partir del siglo vi aC. Por todo ello podemos concluir que las placas documentadas en el yacimiento de Casas del Turuñuelo tienen una cronología que abarca entre principios del siglo vII y principios del siglo vi aC, contemporáneas a las producciones del Bajo Guadalquivir, si bien sufrieron una serie de modificaciones y añadidos, ya en hueso, que debieron producirse en pleno funcionamiento del edifico, en el siglo $\mathrm{v}$ aC.

Somos conscientes de que aún queda un extenso camino por recorrer en lo que a la producción de eboraria se refiere. La ausencia de talleres localizados en enclaves occidentales complica la tarea de definir sus puntos de producción y distribución, así como la proce- 
dencia de sus primeros artesanos, si bien muy pronto, a finales del siglo viII aC, ya podemos hablar de producciones tartésicas. Así mismo, la escasez de análisis sobre los marfiles y los huesos nos impide definir las especies empleadas, lo que a su vez complica el trabajo para establecer las áreas de captación de materias primas y, con ello, las regiones de abastecimiento y los puertos de comercio. Por todo ello, emprender una revisión de los estudios realizados a finales del siglo xx sobre importantes lotes de marfil ayudaría a determinar este horizonte, diferenciando las materias primas y, posteriormente, sus puntos de origen, lo que completaría los nutridos estudios iconográficos con los que hoy en día contamos.

\section{Agradecimientos}

Nos gustaría mostrar nuestro agradecimiento a los investigadores José Ángel Zamora (Escuela Española de Historia y Arqueología en Roma-CSIC) y Bartolomé Mora Serrano (Universidad de Málaga) por sus comentarios respecto de la lectura iconográfica extraída de las placas de Casas del Turuñuelo; sin duda, sus aportaciones han contribuido a mejorar la calidad del presente trabajo.

El trabajo se inserta dentro del Proyecto del Plan Nacional de I+D+i «Construyendo Tarteso: análisis constructivo, espacial y territorial de un modelo arquitectónico en el valle medio del Guadiana» HAR2015-63788-P.

\section{Bibliografía}

ACEVEDO, N. y VERGARA, R., 2009, Técnicas de consolidación de huesos para su conservación, Boletín del Museo Nacional de Historia Natural 58, 121-127.

ALMAGRO-GORBEA, M., 2004, Inscripciones y grafitos tartésicos de la necrópolis orientalizante de Medellín, Paleohispanica 4, 13-44.

ALMAGRO-GORBEA, M., 2008, Objetos de marfil y hueso, en M. ALMAGRO-GORBEA (dir.), La necrópolis de Medellín II. Estudio de los hallazgos, Real Academia de la Historia, Madrid, 401-484.

AUBET, M. E., 1979, Marfiles fenicios del Bajo Guadalquivir I. Cruz del Negro, Studia Archaeologica 52, 15-77.
AUBET, M. E., 1980, Marfiles fenicios del Bajo Guadalquivir II. Acebuchal y Alcantarilla, Studia Archaeologica 63, 33-79.

AUBET, M. E., 1982, Marfiles fenicios del Bajo Guadalquivir III. Bencarrón, Santa Lucía y Setefilla, Pyrenae 17-18, 231-279.

AUBET, M. E., 2008, Los marfiles de Carmona, en El tesoro arqueológico de la Hispanic Society of America, Museo Arqueológico Regional de Madrid, Madrid, 286-298.

BANERJEE, A., SCHUHMACHER, T. X., CARDOSO, J., CASTRO, J. L., FERJAOUI, A., MEDEROS MARTÍN, A., MARTÍNEZ HAHNMÜLLER, V. Y BEN JERBANIA, I., 2017, 
Marfil de hipopótamo procedente de estratos fenicios arcaicos de Útica (Túnez), Madrider Mitteilungen 58, 80-105.

CELESTINO, S., 1997, Santuarios, centros comerciales y paisajes sacros, Cuadernos de Prehistoria y Arqueología Castellonenses 18, 359-389.

CELESTINO, S., GRACIA, F. y RODRÍGUEZ GONZÁLEZ, E., 2017, Copas para un banquete. La distribución de cerámicas áticas en Extremadura, en X. AQUILUÉ, P. CABRERA y M. ORFILA (eds.), Homenaje a Glòria Trias Rubiés. Cerámicas griegas de la Península Ibérica: cincuenta años después (1967-2017), Iberia Graeca, Barcelona, 140-149.

CELESTINO, S. y RODRÍGUEZ GONZÁLEZ, E., 2017, Tarteso en Extremadura, Revista de Estudios Extremeños LXXIII-I, 13-56.

CELESTINO, S. y RODRÍGUEZ GONZÁLEZ, E., 2019, Un espacio para el sacrificio: el patio del yacimiento tartésico de Casas del Turuñuelo (Guareña, Badajoz), Complutum 30-2.

CHO MARTÍNEZ, S. y CHINCHILLA SÁNCHEZ, J., 2008, La conservación y restauración de los materiales arqueológicos de la Cova des Pas, UNICUM 7, 30-54.

COLLINS, B. J. (ed.), 2002, A History of the animal world in the ancient near east, Brill, Leiden-BostonColonia.

CORRADO, P. y PULGA, S., 2010, Pratiche conservative sullo scavo archeologico. Principi e método, All'Insegna del Giglio, Florencia.

ESCACENA, J. L., FERNÁNDEZ FLORES, A. y RODRÍGUEZ AZOGUE, A., 2007, Sobre el Carambolo: un hippos sagrado del santuario IV y su contexto arqueológico, Archivo Español de Arqueología 80, 5-28.

EGOCHEAGA, J. E., 1989, Análisis antropológico en arqueología, en III Congreso de Arqueología Medieval Española, Oviedo, 27 de marzo-1 de abril, 1989, vol. I, Asociación Española de Arqueología Medieval, Oviedo, 69-88.

ELAYI, J. y ELAYI, A. G., 2014a, Phoenician coinages, vol. I-II, supplément to Transeuphratène 18, Gabalda, París.
ELAYI, J. y ELAYI, A. G., 2014b, A monetary and political history of the Phoenician city of Byblos in the fifth-fourth centuries B.C.E., History, Archaeology and Culture of the Levant, 6, Eisenbrauns, Winona Lake, Indiana.

ESPIONZA, E. y MANN, J., 1992, Identification guide for ivory and ivory substitutes, World Wildlife Fund Publication, Baltimore.

FERNÁNDEZ GÓMEZ, F., 1989, La fuente orientalizante de El Gandul (Alcalá de Guadaira, Sevilla), Anejos del Archivo Español de Arqueología 62, 199-218.

GARCÍA FORTES, S. y FLOS TRAVIESO, N., 2008, Conservación y restauración de bienes arqueológicos, Síntesis, Madrid.

GÓMEZ PEÑA, A., 2018, Nueva interpretación sobre la simbología de la bandeja protohistórica de El Gandul (Alcalá de Guadaira, Sevilla), Saguntum 50, 89-105.

GONZÁLEZ DE CANALES, F., SERRANO PICHARDO, L. Y LLOMPART GÓMEZ, J., 2004, El emporio fenicio precolonial de Huelva (ca. 900-770 a.C.), Editorial Biblioteca Nueva, Madrid.

GUNTER, A. C., 2009, Greek Art and the Orient, Cambridge University Press, Cambridge.

LAPÉROUSE, J. F. de, 2008, Conservación de los marfiles y fragmentos de hueso y de concha procedentes de las excavaciones de Bonsor, en $E l$ tesoro arqueológico de la Hispanic Society of America, Museo Arqueológico Regional de Madrid, Madrid, 300-309.

LE MEAUX, H., 2006, Les ivoires “orientalisants" de la péninsule Ibérique: réflexions stylistiques, Mélanges de la Casa de Velázquez 36-2, 187-210.

LE MEAUX, H., 2010a, L'iconographie orientalizante de la Péninsule Ibérique. Questions de styles et d'echanges (VIII ${ }^{e}-V^{e}$ siècles AV. J.-C.), Casa de Velázquez, Madrid.

LE MEAUX, H., 2010b, Los marfiles peninsulares del principio del I milenio antes de Cristo: estado de la cuestión, en B. COSTA y J. HERNÁNDEZ (eds.), Aspectos suntuarios del mundo fenicio-púnico en la Península Ibérica. XXIV Jornadas de Arqueología 
fenicio-púnica (Eivissa, 2009), Govern de les Illes Balears, Eivissa, 111-129.

LUCIAÑEZ TRIVIÑO, M., 2018, El marfil en la Edad del Cobre de la península ibérica. Una aproximación tecnológica, experimental y contextual a las colecciones ebúrneas del mega-sitio de Valencina de la Concepción-Castilleja de Guzmán (Sevilla), Universidad de Sevilla (tesis doctoral inédita).

MALUQUER DE MOTES, J., 1983, El santuario protohistórico de Zalamea de la Serena, Badajoz, II, 1981-1982, Programa de Investigaciones Protohistóricas V, CSIC, Barcelona.

MARÍN AGUILERA, B., RODRÍGUEZ GONZÁLEZ, E., CELESTINO PÉREZ, S. y GLEBA, M., 2019, Dressing the sacrifice: textiles and rituality at the palace-sanctuary of Casas del Turuñuelo, Spain, Antiquity 370, 933-953.

MARTÍN RUIZ, J. A., 2011, Eboraria fenicia. Abastecimiento, producción y comercio del marfil en el Mediterráneo Occidental, Takurunna 1, 83-110.

MARZOLI, D., BANERJEE, A., MARCOS SÁNCHEZ, V. y GALINDO SAN JOSÉ, L., 2016, Elfenbeinwerkstätten aus Huelva und La Rebanadilla (Málaga), den ältesten phönizischen Niederlassungen auf der Iberischen Halbinsel, Madrider Mitteilungen 57, 88-138.

MEDEROS MARTÍN, A. y RUIZ CABRERO, L. A., 2004, El pecio fenicio del Bajo de la Campana (Murcia, España) y el comercio fenicio de marfil, Zephyrus 57, 263-281.

NAEH, L., 2015, In search of identity: the Contribution of Recent Finds to Our Understanding of Iron Age Ivory Objects in the Material Culture of the Southern Levant, Altorientalische Forschungen 42(1), 80-96.

NIEMEIER, W. D., 2014, The Heraion at Samos, en J. ARUZ, S. B. GRAFF e Y. RAKIC (eds.), Assyria to Iberia at the Dawn of the Classical Age, The Metropolitan Museum of Art, Nueva York, 295-301.
OLMOS, R., 2007-2008, El estanque de la diosa. Representaciones de raigambre oriental y mediterránea en la iconografía ibérica, Boletín de la Asociación Española de Amigos de la Arqueología 45, 111-127.

RODRÍGUEZ GONZÁLEZ, E., 2018, El poblamiento del valle medio del Guadiana durante la I Edad del Hierro, Bibliotheca Praehistorica Hispana XXXIV, CSIC, Madrid.

RODRÍGUEZ GONZÁLEZ, E. y CELESTINO, S., 2017, Las estancias de los dioses. La habitación 100 del yacimiento de Casas del Turuñuelo (Guareña, Badajoz), Cuadernos de Prehistoria y Arqueología de la Universidad Autónoma de Madrid 43, 179-194.

RODRÍGUEZ GONZÁLEZ, E. y CELESTINO, S., 2019, Primeras evidencias de un banquete: análisis arquitectónico y material de la estancia s-1 del yacimiento de Casas del Turuñuelo (Guareña, Badajoz), Cuadernos de Prehistoria y Arqueología de la Universidad Autónoma de Madrid 45, 117-200.

ROSAS GONZÁLEZ, A., FORTEA PÉREZ, J., de la RESILLA VIVES, M., FERNÁNDEZ COLÓN, P., HIDALGO GONZÁLEZ, A., LACASA MARQUINA, E., MARTÍNEZ-MAZA, C., GARCÍA TABERNERO, A. y BASTIR, M., 2015, Restos neandertales de la cueva de El Sidrón: una restauración al servicio de la investigación paleontológica, Boletín del Instituto Andaluz de Patrimonio Histórico 53, 70-73.

SCHUHMACHER, Th. X., 2016, Elefanten und Elfenbein auf der Iberischen Halbinsel und in Nordwestafrika. Interdisziplinäre Studien zu Austauschsystemen im 3. und der ersten Hälfte des 2. Jts. v. Chr., Iberia Archaeologica 16-3, Tübingen-Berlin.

TORRES, M., 2000, Tartessos, Real Academia de la Historia, Madrid.

TULEY-NEL, S. L. y ANTONITES, A. R., 2015, Archaeological worked bone and ivory. A guide to best practice in preservation, research and curation, University of Pretoria, Pretoria. 